Florida International University

FIU Digital Commons

FIU Electronic Theses and Dissertations

University Graduate School

$7-22-2020$

\title{
Tourist Responses to Tourism Experiences in Saudi Arabia
}

Faisal Mohammed Aldakhil

falda002@fiu.edu

Follow this and additional works at: https://digitalcommons.fiu.edu/etd

Part of the Hospitality Administration and Management Commons, Marketing Commons, and the Tourism and Travel Commons

\section{Recommended Citation}

Aldakhil, Faisal Mohammed, "Tourist Responses to Tourism Experiences in Saudi Arabia" (2020). FIU Electronic Theses and Dissertations. 4453.

https://digitalcommons.fiu.edu/etd/4453

This work is brought to you for free and open access by the University Graduate School at FIU Digital Commons. It has been accepted for inclusion in FIU Electronic Theses and Dissertations by an authorized administrator of FIU Digital Commons. For more information, please contact dcc@fiu.edu. 


\title{
FLORIDA INTERNATIONAL UNIVERSITY
}

\author{
Miami, Florida
}

TOURIST RESPONSES TO TOURISM EXPERIENCES IN SAUDI ARABIA

\author{
A thesis submitted in partial fulfillment of \\ the requirements for the degree of \\ MASTER OF SCIENCE \\ in \\ HOSPITALITY MANAGEMENT \\ by
}

Faisal Aldakhil

2020 
To: $\quad$ Dean Michael Cheng

School of Hospitality and Tourism Management

This thesis, written by Faisal Aldakhil, and entitled Tourist Responses to Tourism Experiences in Saudi Arabia, having been approved in respect to style and intellectual content, is referred to you for judgment.

We have read this thesis and recommend that it be approved.

Miranda Kitterlin

Nancy Scanlon

Jinlin Zhao, Major Professor

Date of Defense: July 22, 2020

The thesis of Faisal Aldakhil is approved.

Dean Michael Cheng School of Hospitality and Tourism Management

Andrés G. Gil

Vice President for Research and Economic Development and Dean of the University Graduate School

Florida International University, 2020 


\begin{abstract}
OF THE THESIS
TOURIST RESPONSES TO TOURISM EXPERIENCES IN SAUDI ARABIA
\end{abstract}

by

\author{
Faisal Aldakhil
}

Florida International University, 2020

\author{
Miami, Florida \\ Professor Jinlin Zhao, Major Professor
}

A decade ago, the Kingdom of Saudi Arabia (KSA) was not perceived to be a popular tourism destination except for religious purposes, the government of KSA has been proactive in recent years building new destinations, changing longstanding policies, focusing on tourism and hospitality education, and renovating its image to attract domestic and international tourists. Tourism contributed to almost 9\% of the Kingdom's GDP in 2018, around 65 billion dollars (WTTC, 2019). The purpose of this paper is to understand the sentiment that tourists have regarding the new tourism campaigns in KSA, to have transparent feedback about the experiences and services mostly adopted by tourists, and to study the feasibility of KSA Vision 2030 regarding the tourism sector. This study will perform an open data analysis by extracting and analyzing data from a well-known online source (Twitter). Results will highlight the utilization of online data tools to measure tourism trends. 


\section{TABLE OF CONTENTS}

CHAPTER

PAGE

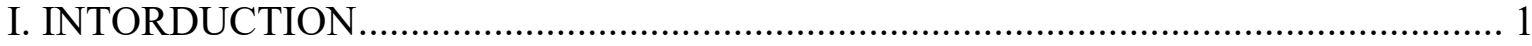

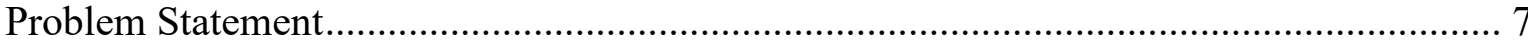

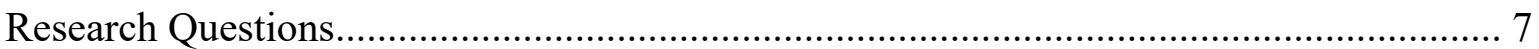

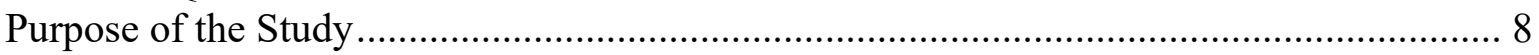

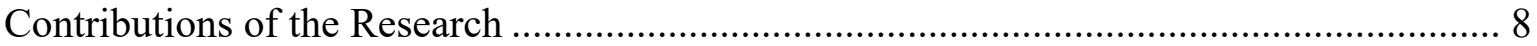

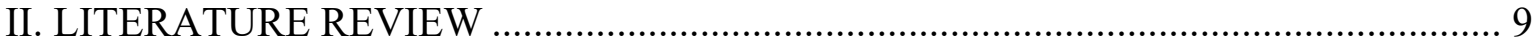

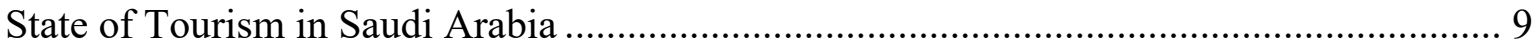

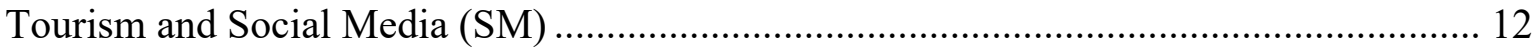

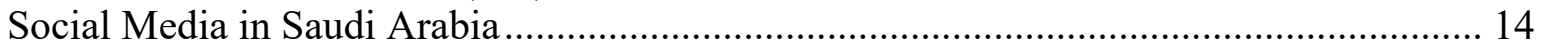

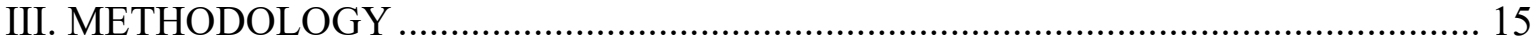

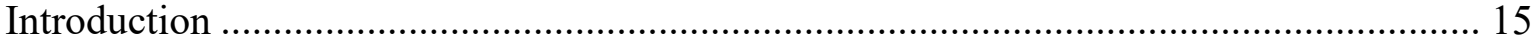

Research Design and The Research Method of Study ................................................ 17

The Reason for Using This Research of Method ………............................................. 18

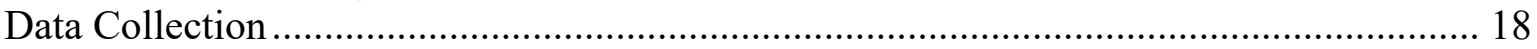

IV. RESULTS

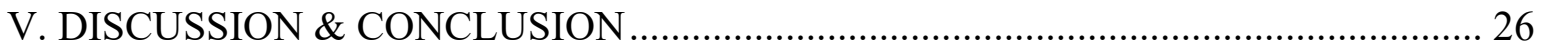

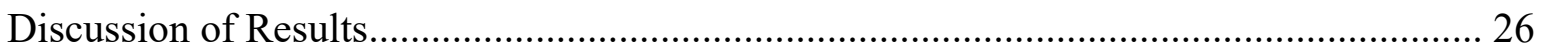

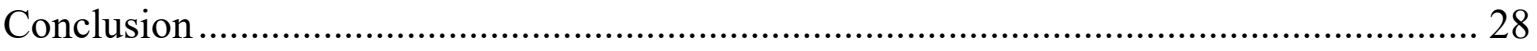

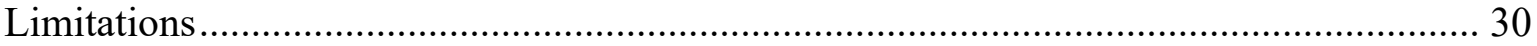

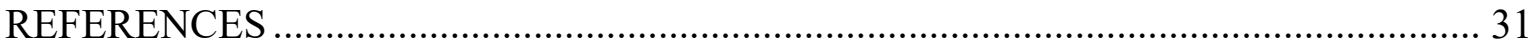


TABLE OF FIGURES

FIGURE

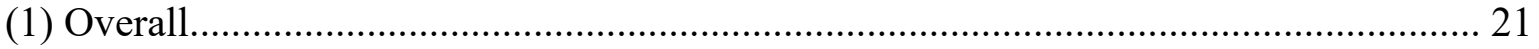

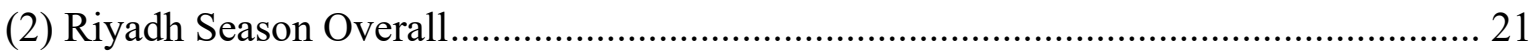

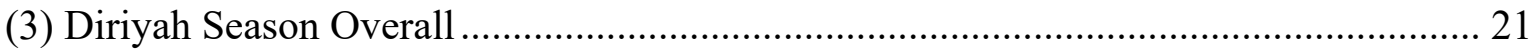

(4) Shita_Tantora Overall ............................................................................................ 22

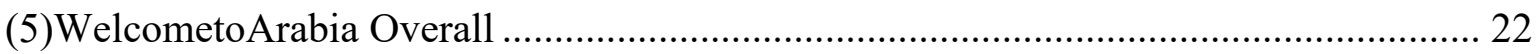

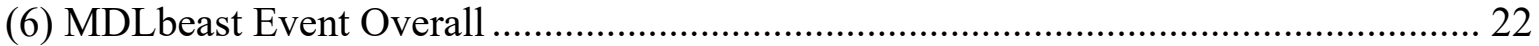

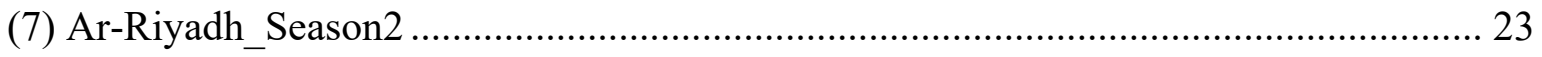

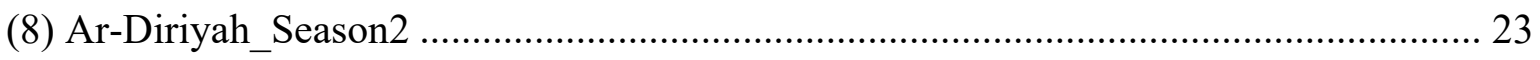

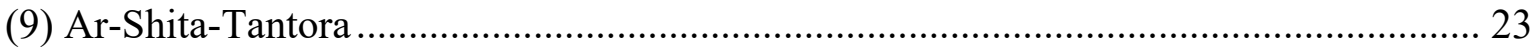

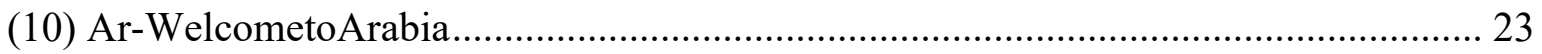

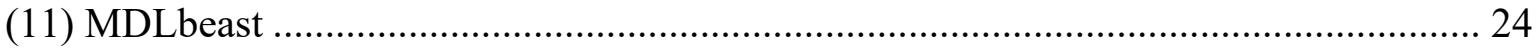

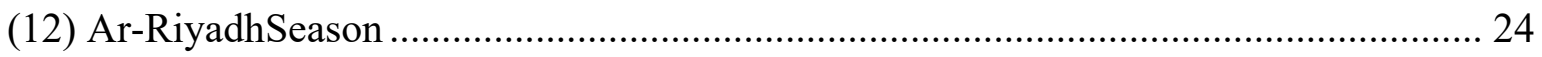

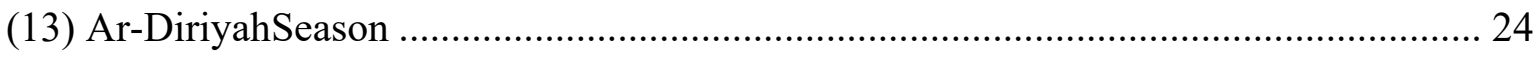

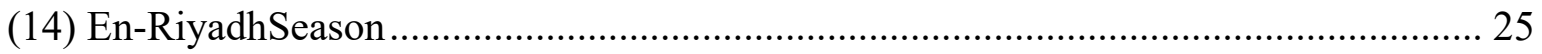

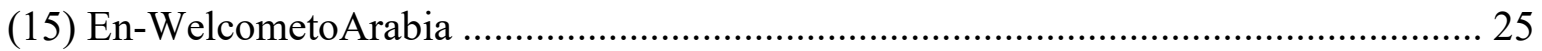

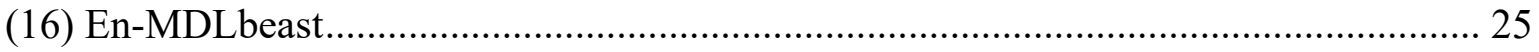

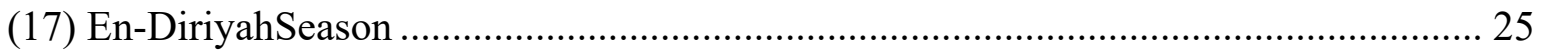

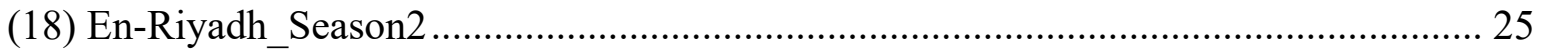

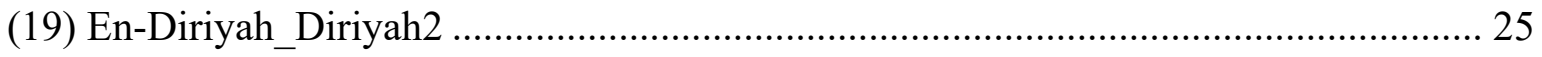

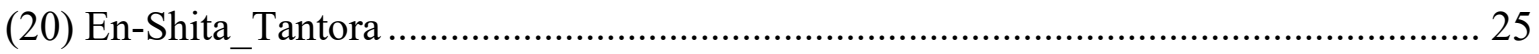




\section{CHAPTER I}

\section{INTRODUCTION}

According to the World Travel and Tourism Council (2019), travel and tourism creates jobs, steers export, and generates elements of prosperity, sustainability, and continuity across the world. It is considered that the sector superficially comprises of travel destinations and tourists' attraction sites, the World Travel and Tourism Council (2019) explains that the industry entails an array of industries from companies and businesses that deal in accommodation and transportation of critical necessities, including foods and beverages, retail, and culture destinations aimed at bringing people of different demographic characteristics together.

In an analysis quantifying the extent and size of the industry, the World Travel and Tourism Council (2019) highlights that the impact of the industry in over 185 world countries contributed to over $10 \%$ of the global gross domestic profit, in turn creating over three hundred million employment opportunities. Statistically, this translated to over ten percent of worldwide jobs. The World Travel and Tourism Council (2019) additionally reports that domestic tourism was on the rise, especially in the developing world, contributing to over $70 \%$ of the spending towards activities of tourism across regions of the world. The council similarly reports that there has been a continued rise in activities of tourism, the rate standing at $3.9 \%$ as of 2018 , outpacing the world's economic growth rate for the ninth consecutive year, thus representing the industry's potential as a favourable choice for governments (World Travel and Tourism Council, 2019). 
There are many factors that influence the gradual, and continuous increase in the flow of travelers across the world, from the advancements in the systems of transports and communication to the advocacy of a free world trade, the World Travel and Tourism Council recognizes the attractiveness of various destinations and the strength of their currencies as important elements in understanding modern day tourism. In fact, the existence of travel and tourism as a vital component that drives economic development, and also as a channel for promoting cultural interactions and diversity serves to justify not only its growing significance, but also in the extent of advancements in transportation and technology across the world (World Travel and Tourism Council, 2019).

\section{Saudi Commission for Tourism and National Heritage}

The tourism industry in Saudi Arabia is still not mature compared to the tourism sector in many developed and developing countries. In 2000, the government established the Saudi Commission for Tourism and National Heritage (SCTH), which used to be responsible for the planning, organizing, and development of the tourism sector. SCTH is seeking to overcome obstacles such as governmental regulations and bureaucracy that the tourism industry faces in general and the tourism investment activity in particular, by working with the private sector and arranging agreements, incentives, and promotional activities. The SCTH focuses on the preservation, improvement and maintenance of the country's enormous archeological treasures, historic sites, and museums that links the Kingdom to ancient civilizations (Saudi Commission for Tourism and Antiques, 2014). In 2015, the previous King Abdullah passed away, and his brother Salman, the second in line as the new King, appointed his son Muhammed bin Salman (MBS) as the new Crown 
Prince. The Crown Prince launched his Vision 2030 setting the blueprint for the strategic plans for the country. Vision 2030, economic diversity plan has declared that in KSA the tourism sector will be one of the main pillars to diversify the economy and decrease the heavy dependence on oil in the coming years (KSA Vision 2030, 2016). In 2020 the Saudi Commission for Tourism and National Heritage became the Ministry of Tourism of Saudi Arabia.

Vision 2030

In Saudi Arabia's vision 2030 economic diversity plan, the country’s leadership underlined the need to develop a vibrant society thriving on the development of economic opportunities, long-term investment, being open for business, and leveraging its unique geographical and cultural positions (KSA Vision 2030, 2016). The leadership aimed at focusing on the development and promotion of culture and entertainment, highlighting that these were critical in the modern organization of societies (KSA Vision 2030, 2016). Moreover, the vision elaborated that the tourism sector would be one of the main pillars in the diversification of the economy in an attempt to decrease the dependence on oil in the upcoming years. In a move to realize this anticipated achievement of diversity, the World Travel and Tourism Council and Saudi Commission for Tourism and National Heritage announced in 2019 that they would cumulatively support the ambitious plan to welcome tourists to Saudi Arabia (World Travel and Tourism Council, 2020). The aim was to achieve over 100 million international and domestic visits into the country by 2030 . The background for this partnership was the fact that travel and tourism directly contributed to a mere $3 \%$ of the country's gross domestic profit, creating only $5 \%$ of jobs in the country, 
in spite of the country's extensive development. At the same time, Saudi Arabia primarily relied on religious visitors, even though the world has risen to become a culturally diverse and integrated society (World Travel and Tourism Council, 2020). The World Travel and Tourism Council (2019) asserted that the potential of tourism in Saudi Arabia is unlimited. The Kingdom not only serves as a source of wealth and resources to its local people, but also exists as a rich and lucrative hub of unexploited culture and history. Hence, travel and tourism promise to create limitless opportunities in the creation of employment, elevating and promoting the understanding of the local Saudi Arabian culture, subsequently transforming the understanding of the country beyond the perception of an oil-rich Arabian nation. In essence, this would serve to rewrite the history of the area (World Travel and Tourism Council, 2020). The plan by Saudi Arabia is to focus on tourism as a source of revenue and also as a provider of opportunities for the generation of wide experiences in a similar manner to other countries including the United States, France, and the United Kingdom. While Saudi Arabia would rely on these advanced economies for the development of an organizational structure, expertise, technology, and other products and services will be contributed by the wealth of resources at the disposal of the country's economic sector. The move to focus on the development of travel and tourism arrives with elements of competitive advantage.

\section{Competitive Advantage}

The country is home to two of the three religious cities of Islam, Mecca and Medina, and as such, around 1.5 billion Muslims are obliged to perform Hajj rituals at least once in their lifetime (Khan, 2014). Not only does the motivation behind the holy cities' 
existence offer a solitary competitive advantage, but it also serves to establish a backbone for proceeding attempts to open the country to a diverse group of tourists. The travel and tourism sector is experiencing a rapid growth in the country and also serves to confer a competitive advantage. Therefore, Khan (2014), asserts that the future vision and mission of the county's leadership in encouraging activities of tourism lies in its ability to build from the religious pilgrimage that has majorly characterized the sector, as well as focusing on developing future visitor experiences. In addition, there are five UNESCO world heritage sites in the Kingdom: Al-Ahsa Oasis, At-Turaif district in ad-Diriyah, historic Jeddah the Gate of Makkah, Rock Art in the Hail Region, and the Al-Hijr Archaeological Site (Madâin Sâlih) in AlUla (UNESCO, 2019).

Vision 2030 Mega Projects

The major four projects announced by the Crown Prince intending to diversify the economic, social, and cultural aspects of the country are 1) Qiddiyah Entertainment City, the world largest recreational and entertainment city presenting theme parks, entertainment centers, sport facilities to host international competitions, training academies, desert tracks for motorsports, water and snow based leisure, safari, and a combination of historical, cultural, and educational events and activities. 2) NEOM, a $\$ 500$ billion project aimed to build a future city from scratch in the North-West of the Kingdom near the Egyptian and Jordanian borders on the Red Sea. NEOM is a technology-based project that will include, several cities, airports and seaports, vacationers' areas, manufacturing complexes, and “innovation centers". 3) the Red Sea Project, a luxurious tourism-based project focusing on tourism, recreation, and sustainability to introduce the untapped natural resources of the 
Red Sea to local its visitors. 4) Amaala Resort, another ultra-luxurious project focusing on wellness, healthy tourism, art, and culture. The ambitious projects aim to be an additional source of income to the country and to transform the quality of the citizens lifestyle providing them with world class tourism and entertainment venues (Hassan, 2019).

\section{Saudi Seasons}

In 2019, under the leadership of the Crown Prince MBS, the Saudi Commission for Tourism and National Heritage (SCTH), which is now the Ministry of Tourism in cooperation with the General Authority for Entertainment (GEA) and Ministry of Culture, General Sport Authority, and The Saudi Exhibition and Convention Bureau, in coordination with all relevant institutions announced the launch of the new tourism initiative called Saudi Seasons.

The Saudi Seasons 2019 initiative involves 11 seasons with numerous activities that were specially tailored to several regions and locations of the kingdom promoting cultural, tourist, and historical features for the first time as an experimental test. The program includes a set of cultural, sports, entertainment, and business events, besides working toward providing quality services such as accommodation and transportation, which were planned to enrich visitor experiences. The experimental stage objective is to develop the appropriate infrastructure and to ensure that the services system is ready for future tourism plans (Saudi Arabian Ministry of Tourism, 2019). 


\section{Problem Statement}

Vision 2030 tries to address two major problems in the Saudi tourism sector, first, the lack of entertainment in the Kingdom created an economic leakage from outbound Saudi tourists visiting other Middle Eastern countries such as the UAE, Egypt, Bahrain, and other international locations such as, London, Paris, and Istanbul. The Saudi Arabian outbound market is expected to reach $\$ 43$ billion by 2025 (Globe News Wire, 2019). Second, around $60 \%$ of international tourists come to Saudi for religious purposes (MAS, 2019). Vision 2030 shifted its strategy from focusing only on the religious tourism to open up its doors to international non-religious visitors by issuing an e-visa to 49 countries including the United States, Canada, Germany, China and others for the first time in its history to stimulate the economy and attract foreign investments (Export.Gov, 2018). As a result, in 2016 the government launched The General Entertainment Authority (GEA), which is responsible for the nation's expanding entertainment sector followed by the announcement of policy changes such as, easing the dress code and gender segregation, removing female travel restrictions, and allowing public musical festivals and concerts. The new approach for the tourism sector and the policy changes have a direct and nondirect economic and social effect on the country which will be analysed in this paper.

\section{Research Questions}

Considering the new changes in the Kingdom's opening up to international tourists, policy changes, building new entertainment and leisure projects and cities, and depending on the 
tourism sector to be a major contributor to diversify the economy, the following questions were formed:

1- What is the degree of acceptance to the new tourism strategy?

2- How has the speed of the new tourism transformation impacted perceptions of the new tourism strategy?

3- What are the biggest challenges facing the tourism sector in Saudi Arabia?

\section{Purpose of the Study}

The study's primary aim is to examine the feasibility of the Kingdom of Saudi Arabia's 2030 vision in respect to the diversification of the travel and tourism industry. As such, the research will analyze Saudi Arabia's travel and tourism campaigns through Social Media (SM), and subsequently gain transparent feedback regarding the responses of visitors to the new tourism strategy and resulting experiences. Specifically, this study aims to better understand reactions to the new tourism strategy in terms of tourist's acceptance, perceptions, and challenges, in turn drawing possible solutions to improve it.

\section{Contributions of the Research}

This research would, therefore, contribute towards the development of critical understanding in various dynamics of travel and tourism in Saudi Arabia highlighting the progress of travel and tourism in Saudi Arabia in respect to its 2030 vision. Additionally, through an evaluation of the significance of online presence in influencing activities of travel and tourism, the research proposes key insights into the current transformation of the 
tourism sector and Vision 2030. Also, the research gives an evaluation of the existent motivations, other than the desirous and ambitious nature of humanity to explore, behind tourists' visits to Saudi Arabia, as well as the act of cultural differences that plays a major role in influencing tourist experiences. Cumulatively, the conclusions of this research would be used to improve the understanding of the nature of travel and tourism in Saudi Arabia.

\section{CHAPTER II \\ LITERATURE REVIEW \\ State of Tourism in Saudi Arabia}

The opening of Saudi Arabia to international travel and tourism, other than the traditional limited categories of work, the Hajj, the Umrah religious rituals, visiting family and friends, or commercial and business personnel, presents researchers with various dimensions. Alalmai and Arun (2020) analyze not only the strengths, weaknesses, opportunities, and threats that come with this move, but also the influences that it has on international relations, especially that between Saudi Arabia and India. The economic impacts, as explained by the World Travel and Tourism Council (2019) reveal both the strong economic potential inherent in the industry, as well as the existent opportunities for governments and leaderships to exploit in generating prosperity and creating jobs across the world, Saudi Arabia being a case in point. The move by the World Travel and Tourism Council to support ambitious plans by the government of Saudi Arabia that, through its leader in a declaration of the country's mission and vision for the year 2030-has echoed the 
aim to achieve a vibrant society with strong roots thriving on economy, exemplify the enormous opportunities in the country's tourism systems (World Travel and Tourism Council, 2020). An insight into the travel and tourism industry by The World Economic Forum (2019) highlighting the competitiveness of the industry, and similarly elaborating on the various country profiles ranks Saudi Arabia at the $69^{\text {th }}$ position in competitiveness, $41^{\text {st }}$ in the presence of an enabling environment, $114^{\text {th }}$ in policy and enabling conditions, $42^{\text {nd }}$ in infrastructural development, and $113^{\text {th }}$ in the natural and cultural resources among other varied aspects of assessment. Generally, Saudi Arabia fails to make it to the top ten countries on various elements that guarantee an edge in the extents of competitiveness, including prices, environmental sustainability, tourist service infrastructure, and cultural resources and business travel among others (World Economic Forum, 2019). While the history of the country in matters of foreign travel and tourism, excluded it from such developments, the discussions by Seyfi and Hall (2019) evaluating the concepts, context, and complexities of the Islamic theocracy and tourism serves to as a basis for developing an understanding of important policies including political, social, and economic characteristics of the country, serves as a basis for the evaluation in this paper.

According to Seyfi and Hall (2019), international tourism development in countries that are built on a theocratic structure faces many challenges, complexities, and conflicts in regard to their policy making, marketing, and gender. Seyfi and Hall explained that tourism was developed distinctively between Muslim countries with every nation having its own national development priorities and policies in addition to markets. Conservative regimes such as Saudi Arabia and Brunei were not interested in investing in the development of international leisure tourism due to its perceived "decadence" and "incompatibility" with 
Islam (Baum \& Conlin, 1997; Sadi \& Henderson, 2005). On the other hand, countries like Malaysia, Turkey, Tunisia, and Morocco have been more sensible toward the economic value of international tourism (Hall, Razzaq, \& Prayag, 2020; Henderson, 2003, Youngsted, 2003). While the Maldives choose the enclave-tourism approach where they isolate the tourists by placing them in fully equipped resorts and hotels away from the local population (Henderson, 2008). Zamani-Farahani and Henderson (2010) argued that tourism development in theocratic environments such as Saudi Arabia and Iran faces several issues. Therefore, it is not encouraged. Seyfi and Hall (2019) also explained that the Islamic theocracy has continually presented a huddle in promoting diverse sociocultural interactions in Saudi Arabia. Islam remains an integral part of the Saudi Arabian society, and while it has successfully shaped the country's governance systems, it stood to influence tourism destinations in the area. On the other hand, Al Bakr and Al Yousef (2017) encouraged the movement toward developing international tourism in the Kingdom due to its significant influence on solving the lack of economic diversification and unemployment problems, which are in perfect alignment with Vision 2030. Al Bakr and Al Yousef pointed that since the main oil producing countries are having difficulties in controlling prices and the oil market, instability and fluctuation is expected to increase. Therefore, oil exporting countries are working towards a new economic diversification strategy (Callen, Time, et al., 2014). Further, Khizindar (2012) explained that the government of KSA was planning to adopt a dual approach to develop the tourism sector. First, it aims to decrease the number of an estimated 5 million Saudi citizens who travel abroad for leisure and entertainment by attracting them to domestic tourism, which will contribute to circulate the spending within the country. The Saudi Arabian Monetary 
Agency highlighted that $3 \%$ of the country's GDP is generated by the tourism sector and the inbound tourism is projected to generate revenues of S.R 103.3 billion (US $\$ 27$ billion) by 2020 . Second, it focuses on encouraging world-wide tourism by gaining a share of the large international tourism market. The Saudi Arabian Tourism Information and Research Center (MAS) highlights the latest statistics regarding the tourism sector in the country. MAS indicates that in 2018 the number of direct jobs in the tourism sector reached 552,556 and the percentage of the Saudization (local employment) in the tourism sector is $22.3 \%$. The total tourist establishments are 72,389 and the occupancy rate for accommodation establishments over the Kingdom is $70.2 \%$ for hotels and $65.5 \%$ for apartments. MAS also pointed out that the Middle East tourist arrivals in 2018 reached 63.3 million tourists and the Kingdom's share from it is $24 \%$, which is 15.3 million tourists; In 2017, the Middle East tourist revenue was $\$ 67.4$ billion and the Kingdom's share from it was $38.7 \%$, which amounted to $\$ 26$ billion (MAS, 2019).

\section{Tourism and Social Media (SM)}

Xiang and Gretzel (2010) explain, the internet exists as a fundamental source of information for emerging trends and experiences, especially in the travel and tourism industry, and has thus served to reshape the way people plan, consume, and subsequently evaluate travel. While on one hand it holds consumers who have had a first-hand experience of the innumerable travel and tourism destinations in the world, on the other is an endless list of websites with opinions from independent agencies and bloggers who continually emancipate on developments, both positives and negatives (Xiang and Gretzel, 2010). According to Xiang and Gretzel the internet has fundamentally changed the 
procession of data on various societal activities. The internet not only exists as an enormous source of information on various emerging world subjects, but also provides an opportunity for the promotion of mega trends that cumulatively serve to influence public opinions, and hence consumer preferences. In the United States, for example, a research conducted in the current decade showed that internet search engines existed as the leading source of information not only in guiding subsequent research studies, but also in influencing decision-making processes regarding various activities. Xiang and Gretzel (2010), therefore, explain that the internet has risen to become a vital wheel in the processing of information relating to persons, destinations, critical discussions, and in economics, it exists both as an important gateway and also as a vital marketing channel through which consumers can evaluate various characteristics of topics they are interested in. Moreover, Sotiriadis \& Van Zyl (2013) discussed the emerging electronic Word-ofMouth (e-WOM) and its impacts on the tourism marketing of destinations and businesses and its influence on tourism consumer behaviour, they arrived at the conclusion that social media is not a "panica"; rather, it's an additional important marketing channel to be intelligently used in integrated communications marketing of tourism services. Pantano, Priporas, and Stylos (2017) explored the using of social media to predict tourists' responses to a tourist attraction, their research pointed to the lack of studies investigating the scope of open-data analysis on predicting tourists' response to a certain destination, while asserting the existence of many studies investigating the effects of online reviews on tourists' decisions. Open data is "data that can be freely used, shared and build on by anyone, anywhere, for any purpose" (Maccani, Donnellan, \& Helfert, 2015). The current nature of the tourism market is data-driven and heavily dependent on data exchange, as the 
continuous growth of peoples' usage of digital information through mobile technologies, the demand for open data in tourism and hospitality research has become strong. Pantano, Priporas, \& Stylos, (2017) important finding is that destination marketers have the ability to evaluate tourists' responses to a certain destination ahead in time and can possibly influence the consumer decision-making by improving marketing strategies accordingly.

\section{Social Media (SM) in Saudi Arabia}

According to the Social Media Report in The Middle East, since 2014 mobile social media in the Middle East and North Africa region (MENA) has more than doubled to 44\%, Saudi Arabia is one of the top five national markets for Snapchat, Twitter, and Youtube (Radcliffe, \& Abuhamid, 2019). A report via Global Media Insights (2019) highlighted that Saudi Arabia's SM annual growth rate is 39\% exceeding the annual global rate $13 \%$. In addition, the active internet users in the country are $89.39 \%$ of population amounting 30.26 million users, and the active SM users are $67.95 \%$ of the population amounting 23 million users. The Kingdom has one of the largest SM presences in the world, with 43.80 million mobile subscribers while mobile penetration reached $129 \%$ of the entire population. For instance, the Kingdom has the world's biggest user share per capita for Youtube platform. (Global Media Insights, 2019). Al-Saggaf and Simmons (2015) report that SM is used for practical purposes including communication on the state of natural disasters emancipating people on the progress of floods between 2009 and 2011, as well as engaging the special interest groups and government institutions on the nature and extents of the problem, hence facilitating in decision making. Primarily, SM existed as a complementary entity in guiding public safety, helping the population to cope with threats, and in turn bridging the gap 
between the government and the people. In a country where democracy tends to be somewhat limited, the use of social media is mainly as a form of communication to the government. The main two findings of Al-Saggaf and Simmons are, First, social media plays a more effective role voicing the public opinions to the government than the traditional media. Second, SM is crucial for reading the emotional state of the people (Al Saggaf \& Simmons, 2015).

\section{CHAPTER III \\ METHODOLOGY}

\section{Introduction}

The emerging tendency for tourism research utilizing SM platforms as means to observe and read trends and patterns, especially in conducting marketing and operational strategies is becoming the new reality for travel and tourism destinations, organizations, and experts. As the internet-based platforms are widely used by travellers sharing their experiences and creating a significant amount of e-WOM, researchers can have access to open data, which could enhance their understanding of their targeted audience (Becken, Alaei, \& Wang, 2019). In addition, Ryden, Kottika, Hossain, Sakri, \& Morrison (2019) provided a conceptual framework of social Media Storms (SMS) for hospitality and tourism managers using the Copenhagen Zoo case study. The researchers found "how and why SMSs are an expression of negative consumer empowerment that brings challenges as well as opportunities. As demonstrated, an SMS can lead to a helix for value creation for the organization, consumers, and society.” (Rayden, Kottika, Hossain, Sakri, \& Morrison, 2019). This paper analyzed several studies using social media and open data to gather 
information about a specific event or a destination by using Sentiment Analysis and opinion mining.

Sentiment Analysis (SA)

According to Oxford Online English Dictionary "Sentiment Analysis is the process of computationally identifying and categorizing opinions expressed in a piece of text, especially in order to determine whether the writer's attitude towards a particular topic, product, etc. is positive, negative, or neutral" ("Sentiment Analysis", 2020). The hospitality and tourism sectors are highly dependent on consumer experience, emotion, and opinion. Therefore, investments in research and development in mining data projecting the consumers sentiment is gaining attraction from several researchers and organizations. Becken, Alaei, \& Wang (2019) conducted a study using Twitter as a source of data to analyze tourist's perception and satisfaction about Gold Coast city in Australia. While, Irawan, Akmalia, \& Masrury (2019) used TripAdvisor website as a mining source for data to highlight tourists' perception towards an Indonesian tourism destination by conducting a Sentiment Analysis and Topic Modeling analytics approach. Moreover, Shimada, Inoue, Maeda, \& Endo (2011) proposed a tourism information analysis system known as P/N classification task to analyze a tourism destination, Lizuka city in Japan and mentioned that "Sentiment Analysis is one of the hottest topics in natural language processing" (Shimada, Inoua, Maeda, \& Endo, 2011). In the events segment research direction, Kirilenco, \& Stepchenkova (2017) produced a comprehensive study analyzing the public discourse concerning Sochi 2014 Winter Olympics in Russia by extracting data from Twitter and conducting a SA to view international and local discussion circulating around the event. 
Furthermore, Park, Chihyung, \& Chae (2015), examine tweets generated by cruise passengers highlighting their main interests and preferences, which provide valuable recommendations for practical marketing strategies to solve business problems. The rise of social media, which has proven to be a valuable source of information as explained by Ramanathan and Meyyppan (2019) who elaborate the relevance of Twitter as an important source of sentiment analysis on people's feedback additionally serve to form a foundation for this research.

\section{Research Design and The Research Method of Study}

In order to answer the above question regarding the degree of acceptance of the possibility of drastic changes in the social and cultural systems of the country to accommodate the increase in the number of foreign travelers coming into Saudi Arabia, as well as the viability of the country's 2030 vision mission in realizing a diversification of its economic strategies through the promotion of foreign activities of travel and tourism, this research will take the form of an exploratory research study. The study will explore both the domestic and international visitor responses in respect to the Saudi Seasons marketing campaign in the country analyzing the thoughts and feelings about the possible westernization of many events and practices. Data will be collected from a social media platform, specifically Twitter. Note: a distinction between tweets from domestic and international tourists could not be made, as the country of origin/residence was not made widely available on Twitter. The data analysis process involves fours steps, data extraction, data filtering, manual sampling, and SA implementation as explained further. 


\section{The Reason for Using This Research Method}

This is the first research using Sentiment Analysis to investigate Saudi Arabia's tourism sector, what makes it interesting is the combination of the country's recent opening for international tourism through issuing an e-visa, the high rise of social media penetration in the region, and the current demographics of the Saudi population, which consists of $60 \%$ under the age of 30 years old (Vision 2030, 2017). Indicating a shift in the people's perception on tourism interests and activities due to the emerging high connectivity of the world population caused by the internet and globalization. The analysis of the research data would be considered to reveal a comprehensive and reliable overview of the state of travel and tourism in Saudi Arabia. The research considered social media and various internet articles and documents as reliable sources of information on the nature of activities of travel and tourism in the country. The study relies on the fact that Twitter has, traditionally, been used to create awareness on the validity of various public policies and promotions. Therefore, exists an inherent belief in the advancements in social media and the eradication of various social obstacles. The case of Saudi Arabia, and the position of the government as a Kingdom places it at a strategic position for the use of such analysis being that the social media has been used traditionally to influence change.

\section{Data Collection}

The first step is the data extraction, all data were gathered through an online hashtag tracker tool service www.trackmyhashtag.com to extract tweets from Twitter, the service uses an Application Program Interference (API) to extract the related metadata of a single tweet including tweet ID, tweet URL, posted time, tweet content and type, client source, 
number of engagement, tweet location, tweet language, user name and ID, user biography, verified or non-verified, profile URL, user followers, and user account creation date. A total number of $(28,875)$ tweets were extracted from hashtags the researcher specified to the service provider. The hashtags (\#) were chosen carefully according to its representation of the most exciting events and locations that were involved in the Saudi Seasons and the tourism marketing campaigns. At the beginning the research choose 8 hashtags \#WelcometoArabia, \#AlUla", \#Riyadh_season2, \#Diriyah_season2, \#Riyadhseason, \#shita_tantora, \#MDLbeast, and \#DiriyahSeason. While considering the language barrier, the number (2) following a hashtag name means that the hashtag is written in the Arabic language. The second step is data filtering, Saudi Seasons announcement started in 2019, which made the researcher exclude most tweets before 2019, as a result, \#AlUla was entirely excluded due to the small number of tweets after the announcement of the campaign. At least a 1000 tweet sample size is the minimum requirement for analyzing a hashtag. The third step is to apply a SA on the data using a reliable API able to recognize and analyze Arabic texts. The research used Mazajak API, which is an online system known for its helpful natural language processing application based on a deep-learning model able to achieve state-of-the-art results on numerous Arabic dialects datasets including SemEval 2017 and ASTD. The API provides three-way sentiment categorization to one of the classes Positive, Negative, and Neutral (Farha \& Magdy, 2019). The Fourth and final step is manually checking random samples to make sure of the results accuracy. 


\section{CHAPTER IV}

\section{RESULTS}

The results point to the fact that most of the identified responses located in Saudi Arabia, $81 \%$ of the responses were written in the Arabic language while 18\% in English. It should be noted that it was impossible to make a certain distinction between domestic and international tweets, as country of origin/residence of each "tweeter" was undefined. Riyadh Season has the largest responses with 15,162 tweets, 37\% positive, 53\% neutral, and 10\% negative. The second largest responses came from Diriyah Season with 4908 tweets, $47 \%$ positive, $45 \%$ neutral, and $8 \%$ negative. The third largest sample is Winter Tantora festival (\#Shita_Tantora) produced 3652 tweets, 61\% positive, 29\% neutral, and $10 \%$ negative. Further, Welcome to Arabia marketing campaign came forth with 2691 tweets, $58 \%$ positive, $31 \%$ neutral, and $11 \%$ negative. Finally, MDLbeast musical festival got 1718 tweets, $52 \%$ positive, $32 \%$ neutral, and $16 \%$ negative. While AlUla that has been excluded from the SA analysis got 744 tweets. The list of figures 1, 2, 3, 4, 5, 6 below illustrate the findings. 
Figure (1)

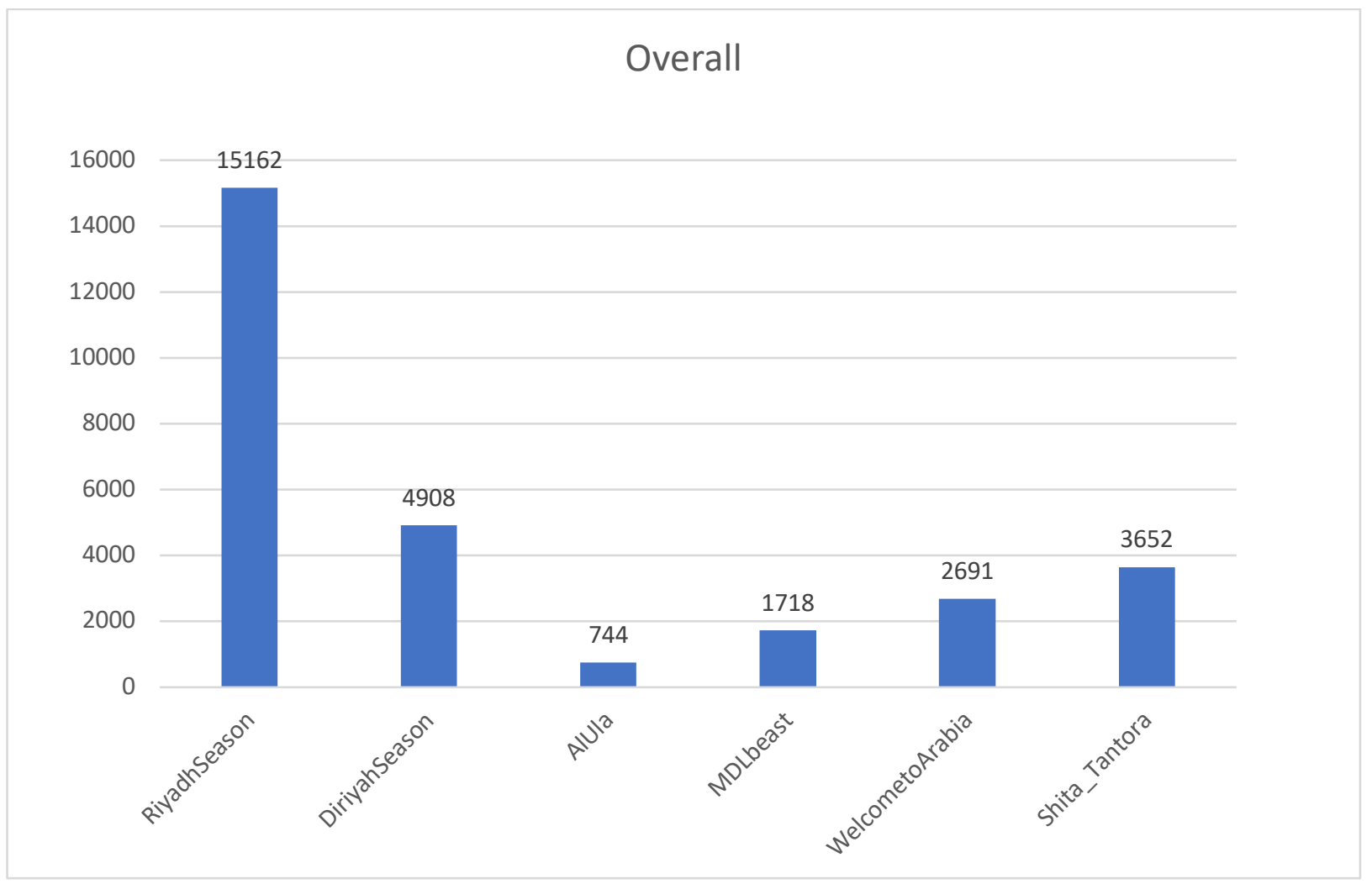

Figure (2)

Figure (3)

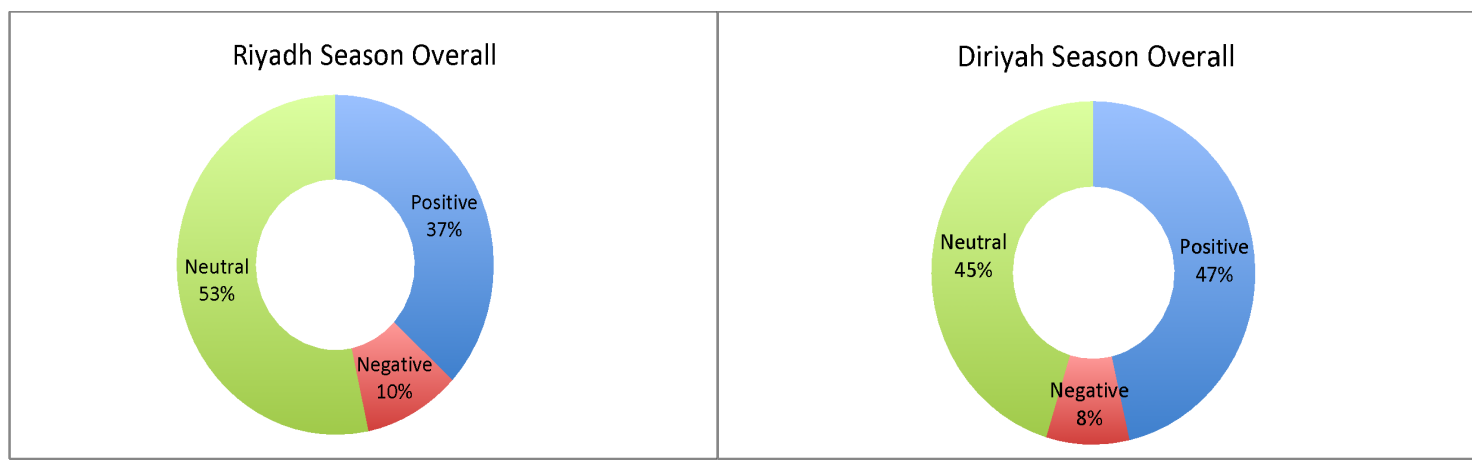




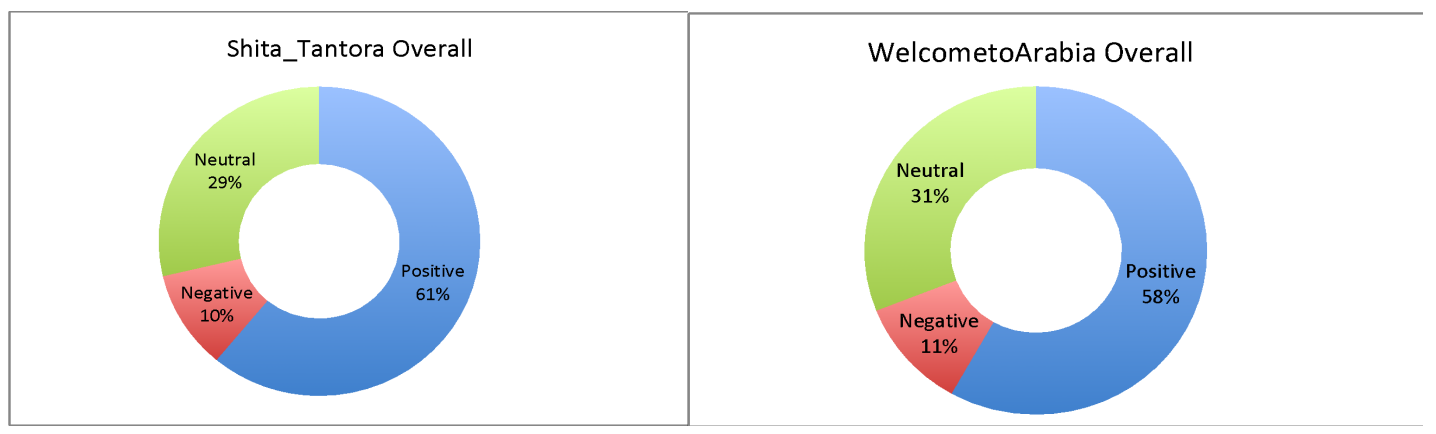

Figure (6)

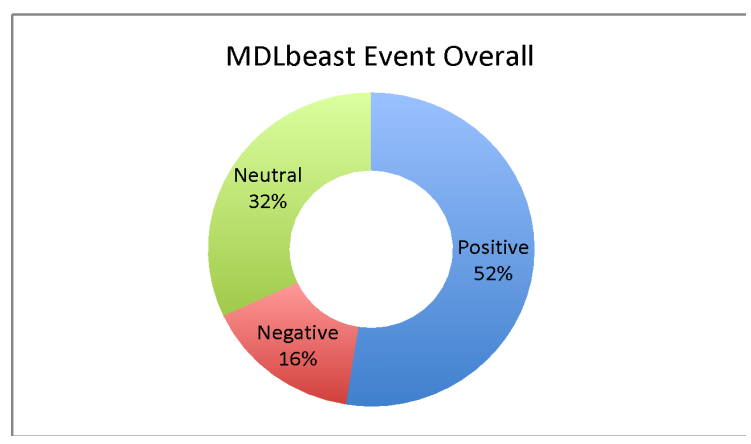

The research divides the results into two segments based on the language of the text, Arabic and English to have an in-depth analysis of the sentiment that was produced:

1- The Arabic text/content tweets stands at 23,458 tweets, the largest portion is \#Riyadh_Season2, which means the hashtag was written in Arabic, 12,856 tweets, 34\% positive, 56\% neutral, 10\% negative. Following, \#Diriyah_Season2 with 4075 tweets, 45\% positive, $46 \%$ neutral, and 9\% negative. The third largest Arabic sample is \#Shita_Tantora with 3590 tweets, $61 \%$ positive, $28 \%$ neutral, and $11 \%$ negative. Further, \#WelcometoArabia has 1292 tweets, $48 \%$ positive, 17\% neutral, and 35\% negative. Next is \#MDLbeast with 887 Arabic tweets, 40\% positive, 38\% neutral, and 22\% negative. 
\#RiyadhSeason written in English got 517 tweets, 45\% positive, 43\% neutral, and 13\% negative. The least Arabic responses, \#DiriyahSeason portrayed 104 tweets, 53\% positive, $36 \%$ neutral, and $11 \%$ negative. List of figures $7,8,9,10,11,12,13$

Figure (7)

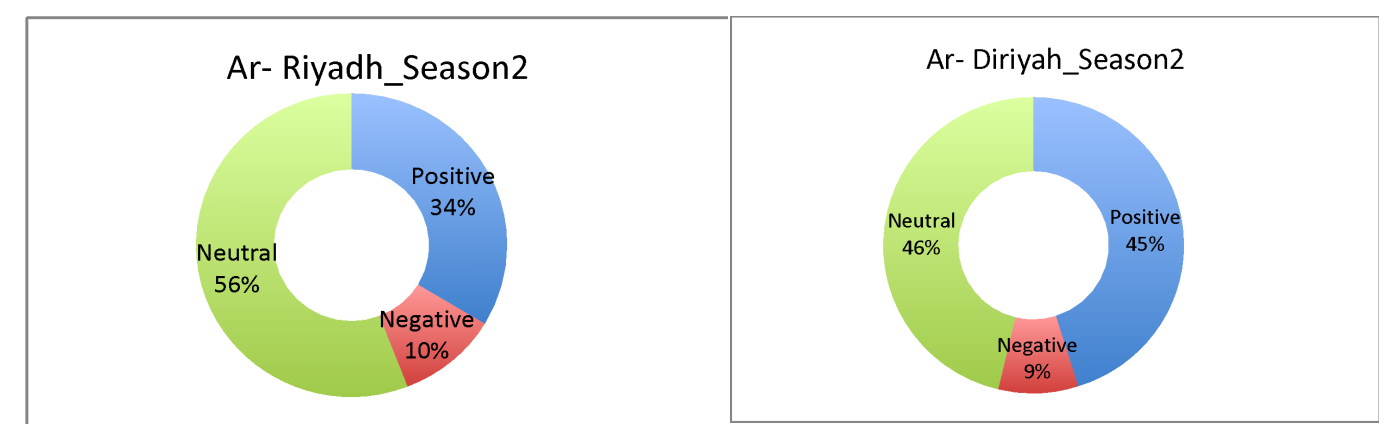

Figure (9)

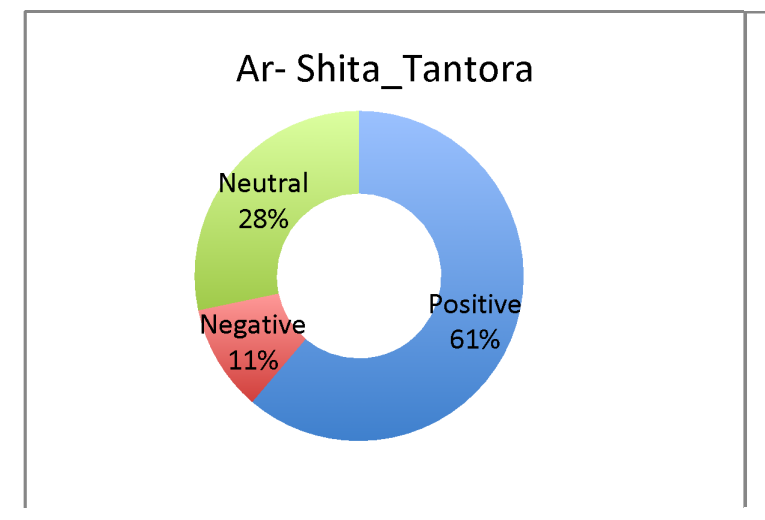

Figure (8)

Figure (10)

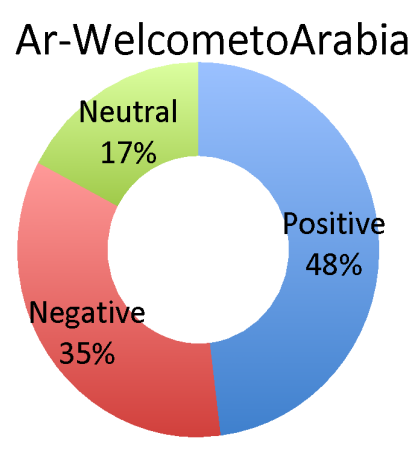




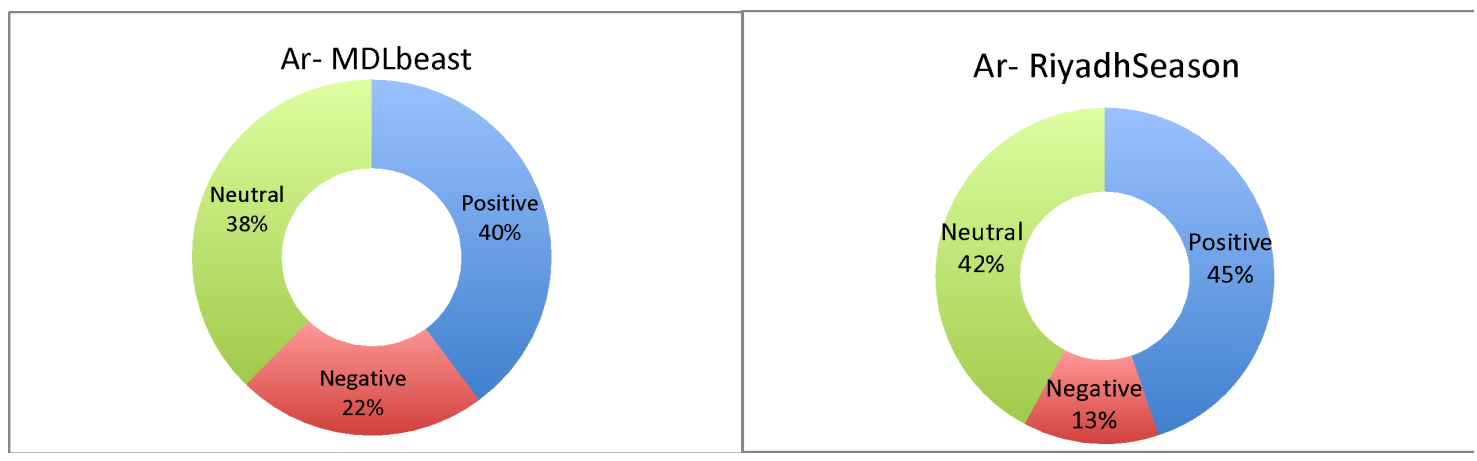

Figure (13)

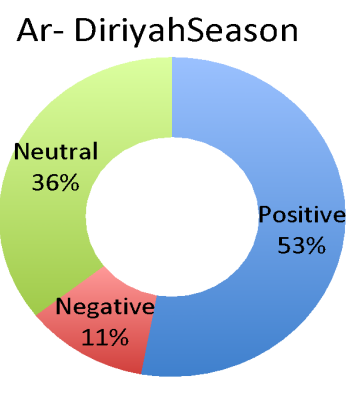

2- The English text/content tweets, which stands at 5417 tweets, \#Riyadhseason being the largest with 1447 tweets, $60 \%$ positive, $36 \%$ neutral, and $4 \%$ negative. Second largest is \#WelcometoArabia with 1399 tweets, 68\% positive, 27\% neutral, 5\% negative. \#MDLbeast came third with $66 \%$ positive, $26 \%$ neutral, and $8 \%$ negative. Next is \#DiriyahSeason with 575 tweets, 58\% positive, 35\% neutral, 7\% negative. Following the Arabic hashtag \#Riyadh_Season2 with 342 tweets, 47\% positive, 48 neutral, and 5\% negative. The Arabic Hashtag \#Diriyah_Season2 comes next with 154 tweets, 40\% positive, 55\% neutral, and 5\% negative. Lastly, \#Shita_Tantora with only 62 tweets, 51\% positive, $47 \%$ neutral, and 2\% negative. List of Figures 14, 15, 16, 17, 18, 19, and 20. 
Figure (14)

Figure (15)

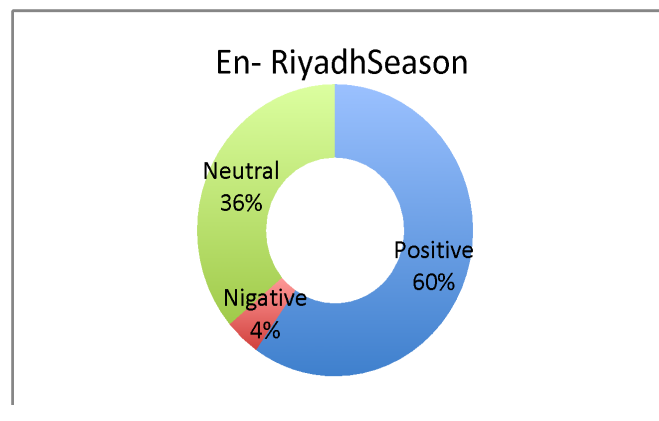

En- WelcometoArabia

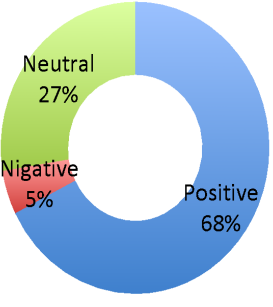

Figure (16)

Figure (17)

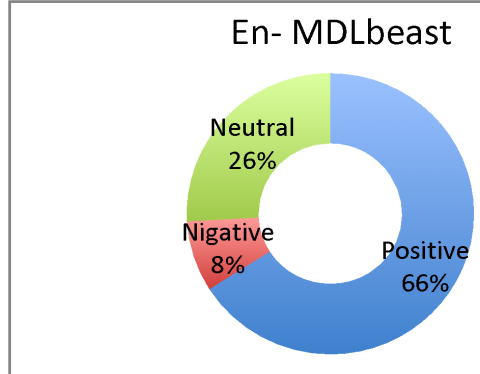

Figure (18)
En-DiriyahSeason

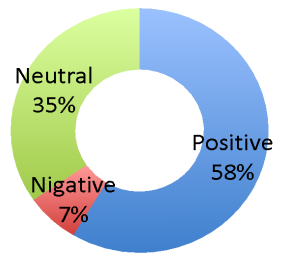

Figure (19)

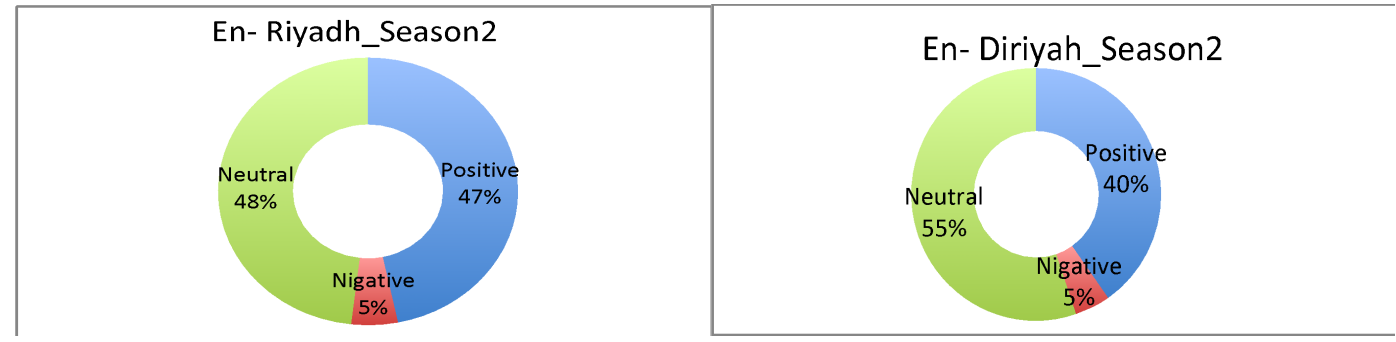

Figure (20)

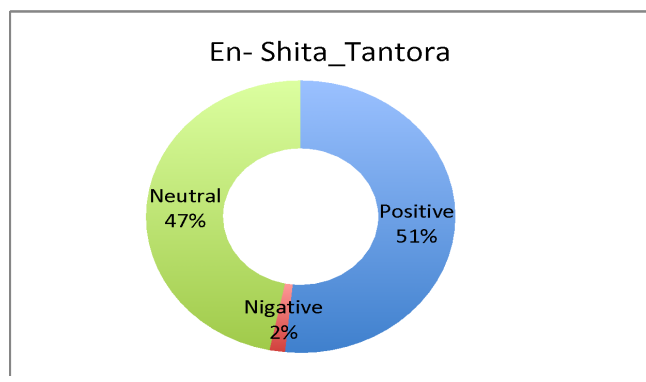




\section{CHAPTER V \\ DISCUSSION \& CONCLUSION}

\section{Discussion of Results}

The results clearly show that Riyadh Season had the most attention due to the fact that Riyadh is the capital of Saudi Arabia and the location where most of the huge events happened. According to Turki Al-Alshaikh the Chairman of the General Entertainment Authority (GEA) Riyadh Season attracted 10 million visitors to the events and 206 thousand tourists, created 34,700 thousand direct jobs and 17,330 indirect jobs, and cash flow during the season exceeded $\$ 1.3$ billion (Shar, 2019). The data clearly show the polarity in the public opinions regarding the events, by dividing the data into an Arabic and English it shows that the English responses were more favourable towards the events, assuming that people who tweeted in English are either Saudis who are more inclined to the western culture or international tourists. While responses in Arabic are leaning towards the conservative segment of the society or people who are not familiar with the western culture. Saudi Seasons presented concerts, cultural and religious events, circuses, theatrical performances, sports events and more (SEERA, 2020). The events in Saudi Season introduced and hosted famous international musicians mainly from the United States and allowed the public to attend without gender segregation for the first time in the history of the country. The data indicate that the negative English tweets of all the hashtags didn't exceed $8 \%$ and approval rate is higher than the Arabic tweets, especially the MDLbeast event where most of the musical concerts happened, while MDLbeast in the Arabic segment scored a negative of $22 \%$ the second highest negative sentiment. The first highest 
negative sentiment is WelcometoArabia in Arabic scoring 35\%, and by manually sampling the hashtag to understand the negative sentiment, found most of the negative sampled responses were tweets mentioning MDLbeast event in an Arabic hashtag that the research did not include in the list of hashtags to be extracted by www.trackmyhashtag.com service. In the overall results were the English and Arabic tweets were combined WelcometoArabia scored the second highest positive sentiment $\% 58$, while MDLbeast scored the highest negative sentiment $16 \%$, MDLbeast scored the highest positive sentiment in the English segment $66 \%$, which exhibit the polarity in the public opinion about the event. On the other hand, Shita_Tantora, which is a winter festival in Al-Ula city featuring classic musical events, UNESCO world heritage site, pre-Islamic ancient sites, world-class restaurants, activities such as hiking, hot air balloon, horse racing and other adventure activities gained the highest overall positive sentiment. Riyadh Season and Diriyah Season exhibits a high percentage of neutrality, Riyadh 53\% and Diriyah $45 \%$, especially when the hashtag is written in Arabic, which indicate that a large segment of the society is still digesting the rapid transformation in the tourism sector, from a segregated community without any public musical festival, to a mix-gender festivals featuring the most famous international musicians, artists, sports teams, and performers. Also, the General Authority cooperated with the artists, sports stars, musicians, Instagram travel influencers coming to the Kingdom to post their experiences in their social media platforms in order to attract international tourists to the country.

According to the Saudi Arabian Tourism Information and Research Center (MAS), the inbound tourism in Saudi Arabia increased from 15.3 million inbound flights in 2018 to 15.5 million in 2019 with a $7.8 \%$ change, and the total inbound tourists nights in the 
hospitality sector grew from 173.9 million in 2018 to 188 million nights in 2019, with $8 \%$ change, and the total inbound tourists expenditure increased from $\$ 24.9$ billion in 2018 to $\$ 26.6$ in 2019 , with $\% 7.8$ change. Whereas the domestic tourism also grew its total domestic trips from 43.3 million flights to 47.5 million amounting a $9.8 \%$ change, the total domestic tourist's accommodation nights increased from 232.1 million to 248.8 million nights, with $7.2 \%$ difference, and the total domestic tourists expenditure grew from $\$ 12.8$ billion in 2018 to $\$ 14.1$ scoring a $10.5 \%$ increase. Looking at the outbound tourism there is also a significant improvement, as the total tourists' outbound flights decreased from 29.1 million trips to 20.6 million, with a $-5.7 \%$ change. And the total outbound expenditure also decreased from $\$ 20$ billion in 2018 to $\$ 18.6$ in 2019, scoring a -7\% change (MAS, 2019). The statistics shows a clear improvement in the travel and tourism sector in the country, and the effectiveness of the new marketing campaign to local and international tourists.

\section{Conclusion}

The research answers crucial parts of the research questions and draw a picture regarding the progress and transformation of travel and tourism sector in the country in respect to its Vision 2030, as the constantly growing international travel and tourism sectors continue to grow, Saudi Arabia strategically positions itself as a possible attractive destination in the global arena, given its unique location and characteristics, economic power, and global partnerships, the Kingdom could have a strong chance to achieve its objective.

Answering the first research question, the degree of local, domestic and international approval can be a major contributor to decide the success of the tourism 
transformation initiative and grant its sustainability. The research illustrates a high percentage of positivity and neutrality and low percentage of negativity, indicating the society's approval or acceptance of the tourism transformation initiatives, while the high percentage of neutrality leads to the second research question asking about the speed of transformation from a religious based tourism to an entertainment hub in the region featuring a combination of religious and non-religious tourism events and activities. Bogari, Crowther, and Marr (2004) found in their case study concerning the motivation for domestic tourism in Saudi Arabia that "the most important push and pull factors as perceived by Saudi tourists are cultural values and religious" (Bogari, Crowther, and Marr, 2004). Despite the fact that this is an old finding, it still has validity in its essence.

Currently it appears that the Saudi tourism priorities regarding its strategy are changing and the new generation of Saudis are craving for global entertainment, leading to a change in perspectives in the tourism sector. In the past three years there were major changes in governmental policies and regulations including the new e-visa, relaxing the dress code and gender segregation, ending female travel and driving restrictions, introducing public musical concerts, and building new leisure and entertainment destinations. The third question addressed the major obstacles in the Saudi Arabian tourism sector. A review of the literature combined with the results of this study suggest that the three major challenges are 1) the government has a crucial task balancing between westernizing the tourism sector without neglecting the cultural and religious values of the society, which ensure an organic and sustainable growth. That has been shown in the negative and neutral sentiments indicating that there are people who oppose the new tourism approach, or they did not approve it yet. 2) despite the positive sentiments shown in the results and the decrease of 
outbound Saudi tourists, the fact that the highest number of inbound tourists are still visiting the country for religious reasons, indicating that the tourism sector in the country still perceived as a religious based tourism, which also presents a challenge to the sector, whether to market itself as a religious destination or a westernized leisure and entertainment destination. 3) The biggest challenge remains economical, the fluctuation of oil prices, which is the main source of income to the country allowing it to build new leisure and entertainment projects and destinations, the future of the sector could be uncertain and dependent on the continuous flow of investments generated from oil revenue, public and private sector engagement, and foreign direct investments.

\section{Limitations}

Sentiment Analysis is still a new method of research in the hospitality and tourism industry, as the API used in this research considered the first one able to analyze Arabic text with high accuracy, there is still room for improvement, for example, the API is not yet able to read emoji's, which is a critical part of social media communication and engagement. Through the random manual sampling of the data, found that some responses were sarcastically positive, the tweet was "the song was a killer" with a happy and loving emoji, but the API classified it as negative. And there are many more similar examples. In addition, the tweet extract service is able to determine the location of the tweet, but a lot of Twitter users do not specify their nationalities/country of origin in their bio section, which makes it difficult to distinguish between international and local tourists. 


\section{REFERENCES}

Alalmai, A. \& Arun, A. (2020). The Strength, Weakness, Opportunity, and Threat Level in Tourism Relations Between India and Saudi Arabia. Engineering and Management. 82(5), $7742-7747$

Ali, A. (2019). Travel and Tourism: Growth Potentials and Contributions to the GDP of Saudi Arabia. Journal Problems and Perspectives in Management, 16(1), 417-427.

Alshammari, B. (2018). An Analysis of Saudi Arabian Outbound Tourism. Retrieved from https://etd.ohiolink.edu/

Becken, S., Alaei, A., Wang, Y. (2019). Benefits and Pitfalls of Using tweets to Assess Destination Sentiment. Journal of Hospitality and Tourism Technology, 30(2), 654660 .

Brian, S., Michael, C., and Kevin, B. (2016). Using Twitter Data for Cruise Tourism Marketing and Research, 33(6), 885-898, DOI: 10.1080/10548408.2015.1071688

Bogari NB, Crowther G, Marr N. (2004). Motivation for domestic tourism: a case study of the Kingdom of Saudi Arabia. Tourism Analysis 8(2): 137-141.

Chaudhry, I. (2014). Hashtags for Change: Can Twitter promote Social Progress in Saudi Arabia, International Journal of Communication, 8(4), 943-96.

Crouch, I., Perdue, R., Timmermans, H., Uysal, M. (2016). Consumer Psychology of tourism, Hospitality, and Leisure. Volume 3.

Ekiz, E., Oter, z., and Stephenson, M. (2017). Tourism Development in the Kingdom of Saudi Arabia: determining the Problems and Resolving the Challenges, International Tourism Development, and the Gulf Cooperation Council States. Pp 124-139.

Farha, I. A., and Magdy, W. (2019). Mazajak: An Online Arabic Sentiment Analyser. In Proceedings of the Fourth Arabic Natural Language Processing Workshop, pp. 192198.

Fazzolari, M. and Petroci, M. (2018). A Study Online Travel Reviews Through Intelligent Data Analysis. Information Technology and Tourism Manuscript, 6-20.

Global Media Insights (2019). Saudi Arabia Social Media Statistics 2019 [Web log post]. Retrieved 2020, from https://www.globalmediainsight.com/blog/saudi-arabiasocial-media-statistics/ 
Globe Newswire. (2019, April 24). Saudi Arabia Outbound Tourism Market Report 20192025: Holiday, Visit Friends and Relatives (VFR), Business (MICE) \& Others (Education, Medical Treatment). Research and Markets. Retrieved 2019, from https://www.globenewswire.com/news-release/2019/04/24/1808591/0/en/SaudiArabia-Outbound-Tourism-Market-Report-2019-2025-Holiday-Visit-Friends-andRelatives-VFR-Business-MICE-Others-Education-Medical-Treatment.html.

Graft, A. (2019). Travel and Tourism Statistics: The Ultimate Collection.

Gretzel, U. (2016). Online Travel Review Study: Role and Impact of Online Travel Reviews.

Hassan, R. (2019). Vision 2030: All you need to know about Saudi Arabia's giga-projects. Retrieved 2020, from https://www.arabnews.com/node/1493976/businesseconomy.

Henderson, J. (2015). Islamic Tourism Reviewed. Tourism Recreation Research, 34(2), 207-211.

Irawan, H., Akmalia, G., and Masrury, R. (2019). Mining Tourist's Perception toward Indonesia Tourism Destination Using Sentiment Analysis and Topic Modelling, 45(2), DOI: https://doi.org/10.1145/3361821.3361829

Khan, S., and Alam, S. (2014). Kingdom of Saudi Arabia: A Potential Destination for Medical Tourism, Journal of Taibah University Medical Sciences, 34(2), 1-14.

Khizindar, T. (2012). Effects of Tourism on Residents' Quality of Life in Saudi Arabia: An Empirical Study. Journal of Hospitality and Management, 21(6), 617-637, DOI: $10.1080 / 19368623.2012 .627226$

Kingdom of Saudi Arabia (2019). KSA Vision 2030: Strategic Objectives and Vision Realization Programs.

Kirilenko, A. and Stepchenkova, S. (2017) Sochi 2014 Olympic on Twitter: Perspectives on Hosts and Guests. International Journal of Tourism Management, 63(4), 54-65.

Maccani, G. Donnellan, B., \& Helfert, M.. (2015). Open data diffusion for service Innovation: An inductive case study on cultural open data services. PACIS 2015 Proceedings, Paper 173. Retrieved from http://aisel.aisnet.org/pacis2015/173.

Marcos, S. (2015). Electronic Word-of Mouth and Online Reviews in Tourism Services: The Use of Twitter by Tourism. Electronic Commerce Research, 13(2), 103-124.

MAS, Tourism Information \& Research Center. (2019). 2019 Travel \&Tourism Monthly 
Statistical Bulletin. Saudi Commission for Tourism and National Heritage.

Retrieved from http://www.mas.gov.sa/publications

Mohammed, A. and Ahmed, A. (2017). Tourism development Effect on Saudi Economic Diversification, Saudi Arabian Monetary Authority.

Munar, A. and Jacobsen, J. S. (2014). Motivations for Sharing Tourism experiences through Social Media. Journal of Tourism Management, 43(1), 46-54.

Pantano, E., Prisporas, C., Stylos, N. (2017). 'You Will Like It!' Using Data to Predict Tourists' Response to a Tourist Attraction. Journal of Tourism Management, 60(4), 430-438.

Radcliffe, Damian \& Abuhmaid, Hadil. (2020). Social Media in the Middle East: 2019 in Review. SSRN Electronic Journal. 10.2139/ssrn.3517916.

Ramanathan, V. and Meyyapan, T. (2019). Twitter Text Mining for Sentiment Analysis on People's feedback about Oman Tourism. 4th MEC International Conference on Big Data and Smart City (ICBDSC), Muscat, Oman, 2019, pp. 1-5, doi:10.1109/ICBDSC.2019.8645596.

Rasoolimanesh, M., and Jafar, M. (2016). Community Participation Toward Tourism Development and Conservation program in Rural World Heritage Sites

Riyadh, A. (2019). Riyadh Season Witnesses Over $\$ 41$ million in Financial Operations.

Ryden, P., Kottika, E., Hossain, M., Skare, V., and Morrison, A. (2019). Threat or Treat for Tourism Organizations? The Copenhagen Zoo Social Media Storm, International Journal of Tourism, 22(3), 108-119.

Saggaf, Y., and Simmons, P. (2015). Social Media in Saudi Arabia: exploring its Use During Two Natural Disasters. International Technological Forecasting and Social Change. 95(3). 3-15.

Saudi Arabian Ministry of Tourism (2019). Launching the "Saudi Seasons 2019" Program. Retrieved January 5, 2020, from https://mt.gov.sa/en/mediaCenter/News/MainNews/Pages/a-m-1-27-2-19.aspx

Schwab, K. (2019). World Economic Forum: The Travel and Tourism Competitiveness Report 2019: Travel and Tourism at s Tipping Point, Insight Report.

SEERA (2020). Decoding the Saudi Arabia Travel and Tourism Industry: Understanding Inbound, Outbound, and Domestic Travel Trends.

Sentiment Analysis. (2020). In Oxford Online Dictionary. Retrieved 
from https://en.oxforddictionaries.com/definition/sentiment_analysis

Seunghyun "Brian" Park, Chihyung "Michael" Ok \& Bongsug "Kevin" Chae (2016) Using

Twitter Data for Cruise Tourism Marketing and Research, Journal of Travel \&

Tourism Marketing, 33:6, 885-898, DOI: 10.1080/10548408.2015.1071688

Seyfi, S., and Hall, M. (2018). Deciphering Islamic Theocracy and Tourism:

Conceptualization, Context, and Complexities. International Journalism Tourism Research. 21:735-746.

Shar, A. (2019). Turki Al Alshikh: GEA Revenue from Riyadh Season Exceeds 5 billion SAR. Sabq. Retrieved 2020, from https://sabq.org/CJdMcy

Shimada, K., Inoue, S., Maeda, H., and Endo, T. (2011). Analyzing Tourism Information on twitter for a Local City. In Proceedings of the First ACIS International Symposium on Software and Network Engineering, 61-66

Sotiriadis MD, Van Zyl C. (2013) Electronic word-of-mouth and online reviews in tourism services: the use of twitter by tourists. Electron Commerce Res 13(1):103-124

Trip Barometer (2018). Global Report: A Unique Global Study Uncovering Global Travel Trends.

World Travel and Tourism Council. (2019). World Travel and Tourism Council and Saudi Commission for Tourism and National heritage Announce to Support Ambitious Plan to Welcome Tourists to Saudi Arabia. Vision 2030 Plan Aims to Make Saudi Arabia Top Five Global Destinations.

World Travel and Tourism Council. (2019). World Travel and Tourism Economic Impact 2019.

Xiang, Z., and Gretzel, U. (2010). Role of Social Media in Online Travel Information Search, Journal of Tourism Management, 31(5), 179-188.

UNESCO. (2019). Saudi Arabia. Retrieved from https://whc.unesco.org/en/statesparties/sa

Vision 2030 (2016). National Transformation Program 2020: Kingdom of Saudi Arabia. Retrieved from http://vision2030.gov.sa/sites/default/files/NTP_En.pdf

Yousif, M., and Bakr, A. (2017). Tourism development Effect on Saudi Economic Diversification, Economic Research Department, SAMA Working Paper. Pp 2-19.

Zaidan, E. (2015). Dubai as a First-Choice Destination for Saudi Tourists: Analysis of Socio-economic Characteristics, Travel Behaviour, and Perceptions. The Arab World geographer, 18(4), 262-281. 